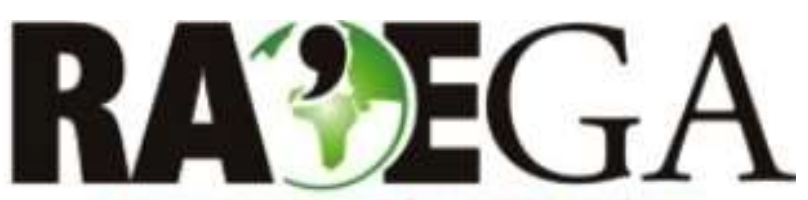

O ESPACO GEOGRÁFICO EM ANÁL.ISE

\title{
A MORFODINÂMICA DA BACIA HIDROGRÁFICA DO RIO TENENTE AMARAL - MT ${ }^{1}$
}

\section{THE MORPHODYNAMIC OF RIVER BASIN TENENTE AMARAL - MT}

\author{
Cleberson Ribeiro de Jesuz \\ Universidade Federal Do Mato Grosso- UFMT \\ Cuiabá, MT, Brasil \\ e-mail: cleberufmt@hotmail.com \\ Ivaniza de Loudes Lazzarotto Cabral \\ Universidade Federal Do Mato Grosso- UFMT \\ Cuiabá, MT, Brasil \\ e-mail: ivanizacabral@hotmail.com
}

\section{Resumo}

A bacia hidrográfica do Rio Tenente Amaral - BHTA, afluente do alto Rio São Lourenço, encontra-se sobre a morfoestrutura da Bacia Sedimentar do Paraná. É uma área constituída por superfícies muito utilizadas pela atividade agropecuária moderna, especificamente na parte planáltica do sudeste matogrossense (Planalto dos Guimarães), onde estão situadas grande parte das principais nascentes dos rios que formam $40 \%$ do Pantanal Setentrional. Neste contexto, levou-se em consideração a bacia do rio Tenente Amaral como área de estudo, contextualizando seus processos morfodinâmicos, por intermédio da produção e análise de materiais cartográficos das determinantes ambientais (clima, litoestratigrafia, solos, clinografia, hipsometria e outros) e socioeconômicas (uso da terra), utilizando as técnicas de geoprocessamento e interpolação de dados espaciais das imagens de satélites SPOT TM5, LANDSAT 5 e dados do modelado do terreno SRTM. A bacia hidrográfica do

\footnotetext{
${ }^{1}$ Programa de Pós-Graduação em Geografia da Universidade Federal de Mato Grosso (Bolsa de Mestrado - CAPES); à Fundação de Amparo à Pesquisa do Estado de Mato Grosso FAPEMAT (Projeto Edital no 009/2009 - PRONEX); à Empresa Brasileira de Pesquisa Agropecuária - EMBRAPA (Projeto Rede Agro-Hídro, Chamada 01/2012 - Macroprograma 1); e ao Conselho Nacional de Desenvolvimento Científico e Tecnológico - CNPq (Projeto MEC/MCTI/CAPES/CNPq/FAPs, no 61/2011) pelo financiamento e apoio prestado a essa pesquisa.
} 
rio Tenente Amaral, apresenta sua área nas unidades morfoesculturais da Depressão Interplanáltica de Rondonópolis e do Planalto dos Guimarães, onde predominam os processos de recuo da superfície planáltica onde se destacam as feições geomorfológicas de escarpas erosivas, depósitos coluvionares, superfícies exumadas, morros testemunhos e vales encaixados na primeira unidade morfoescultural, bem como áreas com ocorrência de erosão superficial e voçorocamentos em meio agropecuário na segunda morfoescultura.

Palavras-chave: Morfodinâmica; Geomorfologia; Feições geomorfológicas; Meio físico-biótico.

\begin{abstract}
The Tenente Amaral River Basin - TARB, tributary of the upper Sao Lourenço River, is on the Morphostructure of the Paraná Sedimentary Basin. It is an area consisting of surfaces widely used by modern agricultural activities, specifically in the plateau of the southeast Mato Grosso state (Planalto dos Guimarães), where are located most of the main sources of the rivers that comprise $40 \%$ of Northern Pantanal. In this context, we took into consideration the Tenente Amaral river basin as study area, contextualizing their morphodynamic processes, through the production and analysis of cartographic materials of environmental factors (climate, lithostratigraphy, soils, clinography, hypsometry and others) socioeconomic (land use), using GIS techniques and interpolation of spatial data from SPOT TM5 satellite images, Landsat 5 and modeled data from the SRTM terrain. The Tenente Amaral, river basin presents its area in morphosculptural units Depressao Interplanáltica Rondonópolis and the Planalto dos Guimarães, whose the plateau dominates the surface of the indentation process marked by the geomorphological features of erosive slopes, colluvial deposits, exhumed surfaces, monadnocksand valleys surrounded by mountains in the first morphoscultural unit, as well as areas with occurrence of soil erosion and agricultural gully processes amid the second morphosculpture.
\end{abstract}

Key-words: Morphodynamics; geomorphology; Geomorphological Features; Physical biotic environment.

\title{
1. INTRODUÇÃO
}

A distribuição geográfica das formas topográficas é um fato inerente à dinâmica da natureza, característica atrelada a resiliência de sua capacidade reguladora, perfazendo a essência de sustentação da própria vida terrestre. Tal concepção é empregada para afirmar o pujante crescimento social e consequentemente econômico, tendo-a como meio de exploração, nunca relação desigual e descontrolada (DREW, 1986; VITTE, 2008). Idéia evidenciada nos entendimentos e consensos científicos desenvolvidos ao longo da evolução humana, ao abordar a máxima sociedade versus natureza (REIS 


\section{A MORFODINÂMICA DA BACIA HIDROGRÁFICA DO RIO TENENTE AMARAL - MT}

JÚNIOR, 2007; SUERTEGARAY e NUNES, 2001; CAMARGO, 2003; FERREIRA, 2010).

Nesse contexto a geomorfologia tem por objetivo analisar as formas do relevo, buscando compreender os processos pretéritos e atuais, sendo este um conhecimento específico e sistematizado (CHRISTOFOLETTI, 1976; MENDONÇA, 2001). Como parte da temática geográfi-ca, constitui importante subsídio para a apropriação racional do relevo, como recurso ou suporte, considerando a conversão das propriedades geoecológicas em sócioreproduto $\neg$ ras. Seu objeto de estudo é a superfície da crosta terrestre, apresentando uma forma específica de análise que se refere ao relevo (MAMEDE, 2000; PEDROSA, 2014). A análise incorpora o necessário conhecimento do jogo de forças antagônicas, sistematizadas pelas atividades tectogenéticas (endógenas) e mecanismos morfoclimáticos (exógenos), responsáveis pelas formas resultantes (CASSETI, 1991; VITTE, 2001).

O estudo do relevo por meio da individualização e compreensão da origem das diferentes características possibilita analisar os aspectos que individualizam a área em estudo, viabilizando o entendimento das formas de evolução do relevo e a compreensão dos processos morfodinâmicos atuantes (BORGES, 2008). E ainda, apresenta uma importância direta no processo de ocupação, compreendendo observações relativas aos diferentes níveis topográficos e características do relevo. O estudo da geomorfologia possibilita a análise espaço-temporal dos processos atuantes no modelado do relevo terrestre, e permite identificar ou prever processos de degradação ambiental relacionados aos elementos físicos presentes em uma determinada área (CASSETI, 2005).

Nesta perspectiva, Ross (2006) destaca que a análise geomorfológica constitui um importante instrumento de análise e determinação de ações preventivas ou mitigadoras para evitar impactos ao meio ambiente.

A Geomorfologia surge nessa pesquisa como fonte de conhecimento da esfera ambiental, cujo objetivo fundamenta-se na elucidação da evolução das formas do relevo em um dos diversos ambientes do Estado de Mato Grosso. 


\section{A MORFODINÂMICA DA BACIA HIDROGRÁFICA DO RIO TENENTE AMARAL - MT}

Tal abordagem fica clara quando Riser (1995, p.104) busca expor esse contexto em sua explanação, onde a,

[...] geomorfologia, e mais geralmente a geografia física, ocuparam durante muito tempo um lugar eminente na pesquisa geográfica. Esta primazia era resultante das descobertas que, graças à geomorfologia, permitiam o estudo do modo como se formaram os relevos e o estudo do modelados e dos paleoclimas, e mais recentemente a descoberta da evolução holocênica e atual suscitada por uma procura social preocupada com planejamentos e riscos maiores.

O Estado de Mato Grosso, assim como o contexto regional do CentroOeste brasileiro, passou nas últimas décadas, especialmente a partir das décadas de 1960 e 1970, por inúmeros avanços técnico-populacionais com apropriação das áreas de Cerrado, sob continuo processo de consolidação do agronegócio, tendo como resultado elevado grau de intervenção nos elementos sistêmicos de cobertura vegetal, junto com o biológico, hídrico e antrópico. Estes foram substituídos e/ou alterados pela pastagem ou pela monocultura mecanizada e, em muitos casos pelas duas modalidades conjuntas. Paralelamente a este fluxo interventor, numa escala mais específica da questão, estão os fatos relacionados à dinâmica de superfície, responsáveis pela geração do recurso apropriado pela referida atividade, ou seja, intervenção na dinâmica dos sistemas morfopedológicos (ROSS, 1991; 2006).

A produção agrícola em escala empresarial no Estado de Mato Grosso ocorre quase exclusivamente nas unidades morfoesculturais dos Planaltos dos Parecis e dos Guimarães, devido às próprias condições topográficas dos mesmos (CABRAL et al., 2013). Em se tratando de um ambiente morfopedológico apropriado para o desenvolvimento de uma agricultura ostensiva e mecanizada, as superfícies do Planalto dos Guimarães foram intensamente ocupadas por grandes propriedades agrícolas dedicadas principalmente à cultura da soja, milho, algodão, cana de açúcar e pecuária extensiva com o objetivo de gerar divisas para economia estadual e nacional.

Diante dessa conjuntura o trabalho buscou identificar e mapear as principais unidades morfodinâmicas da Bacia Hidrográfica do rio Tenente 
Amaral - MT, por meio da obtenção das informações correlacionadas às determinantes de morfoestrutura, morfoesculturas, morfopedologia, clinografia e hipsometria da referida bacia, por interpolações e aplicações das técnicas do Geoprocessamento.

\subsection{CARACTERIZAÇÃO DA ÁREA DE ESTUDO}

A bacia do rio Tenente Amaral está localizada a cerca de $120 \mathrm{~km}$ a sudeste da capital matogrossense, Cuiabá. Entre as coordenadas $15^{\circ} 08^{\prime \prime} \mathrm{S}$ a $16^{\circ} 00^{\prime \prime}$ e $55^{\circ} 05^{\prime \prime} \mathrm{W}$ a $55^{\circ} 35^{\prime \prime} \mathrm{W}$, apresentando uma área de aproximadamente $859 \mathrm{~km}^{2}$. O rio Tenente Amaral, afluente da margem direita do alto São Lourenço, possui como principais tributários os córregos: Brilhante, Cachoerinha e Saia Branca, Figura 01. Sua área de contribuição tem sua maior parcela situada no município de Jaciara - MT, com pequenas porções do seu setor de cabeceiras nas áreas dos municípios de Campo Verde e Santo Antônio de Leverger.

Em termos de flora, de acordo com Brasil (1982) a bacia do rio Tenente Amaral, encontra-se em área de domínio da Savana Arbórea Residual (Cerrado) e remanescente de Floresta Estacional Semidecidual. Entretanto, é uma área que sofre intensa intervenção antrópica relacionada às atividades agropecuárias modernas (WWF BRASIL, 2011). A vegetação natural remanescente, incluindo as Matas Ciliares, possui abrangência de somente 23\% de toda a área da bacia (JESUZ et al., 2013). 


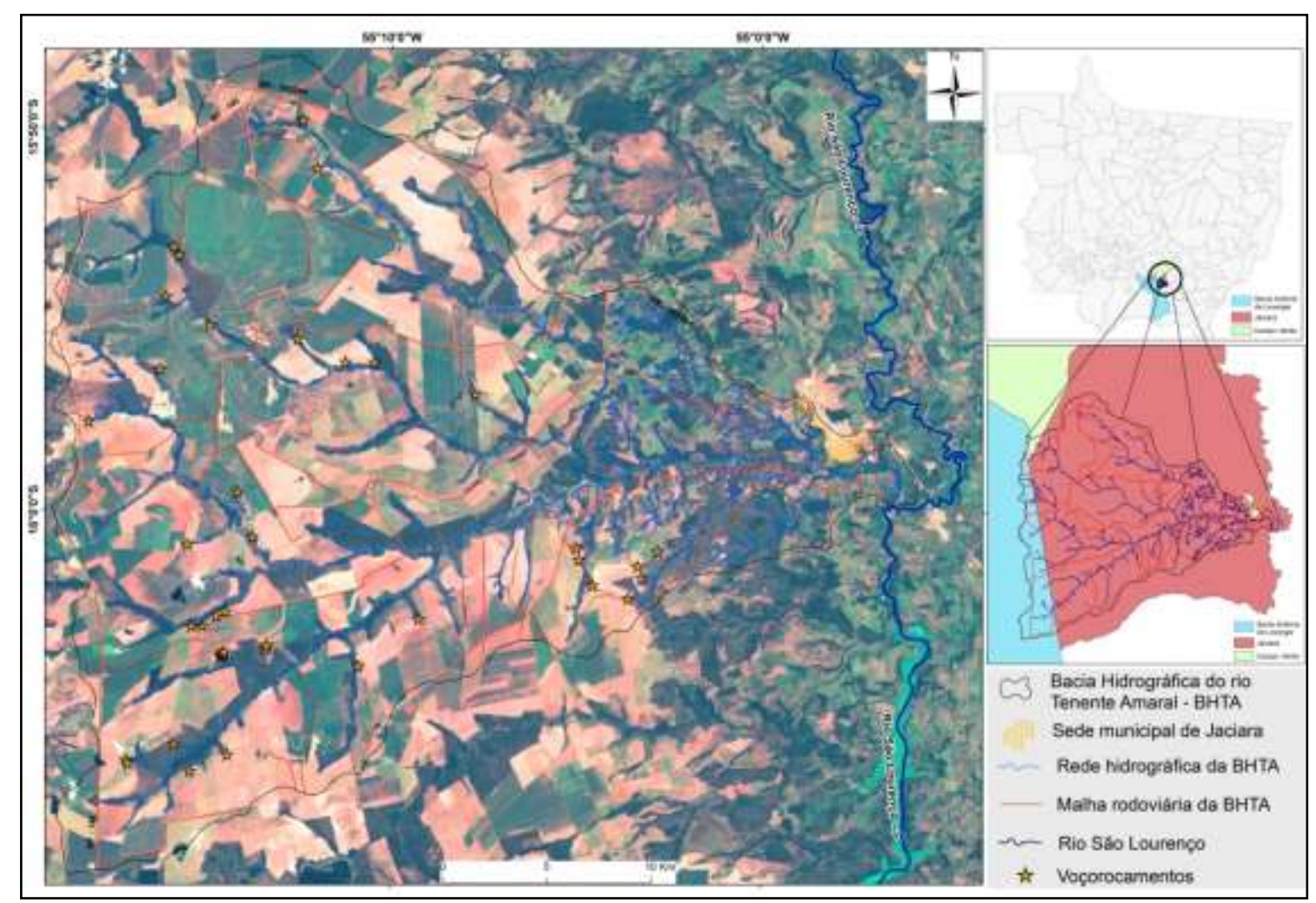

Figura 01: Bacia Hidrográfica do Rio Tenente Amaral - MT. Fonte: LANDSAT 5 - Bandas: 543.

Por ser uma área situada no Planalto e Chapada dos Guimarães a referida bacia tem como principal arcabouço as litologias da bacia é composta por três Formações: da Formação Furnas, Grupo Rio Ivaí e Superfície Paleogênica Peneplanizada com Latolização. A primeira constitui os materiais litológicos do Eon Fanerozóico - Era Paleozóica - e, do Período Devoniano, pertence ao Grupo Paraná, e apresenta como principais componentes os arenitos ortoquartizíticos de granulometria grosseira e localmente finos. $\mathrm{Na}$ base apresentam horizontes conglomératicos monomíticos de espessura média. A segunda, Grupo Rio Ivaí, se remeta aos materiais da Era Paleozóica, do Período Ordivício-Siluriano, é constituida por arenitos finos em bancos espessos e maciços, ocasionalmente grosseiros e conglomeráticos em posições basais. A terceira e última corresponde às superfícies da Era Cenozóica, do Período Terciário, é constituída por paleossolos argilosos e argilo-arenosos microagregados de coloração vermelho-escura. Podem 


\section{A MORFODINÂMICA DA BACIA HIDROGRÁFICA DO RIO TENENTE AMARAL - MT}

apresentar na base crosta ferruginosa, raramente com nódulos concrecionários de caulinita sotopostos às crostas ferruginosas (SEPLAN, 2007; CAMARGO, 2011).

As unidades pedológicas comuns na área são as constituídas principalmente pelas variedades de Latossolos Vermelho, Latossolos Vermelho-Amarelo, Neossolos Quartzarênico e Argissolos Vermelho-Amarelo (EMBRAPA, 1999; 2006, e SEPLAN, 2007).

Em referencia ao ambiente climático, conforme Tarifa (2011), a área em questão faz parte da que está sob a influência da terceira macrounidade climática, ou seja, a de Clima Tropical Continental Alternadamente Úmido e Seco das Chapadas, Planaltos e Depressões de Mato Grosso, com médias pluviométricas anuais de $1650-2100 \mathrm{~mm}$.

Sobre as questões de ordem socioeconômicas, a área pertence a bacia hidrográfica do rio Tenente Amaral faz parte dos setores do Estado onde ocorreu e ainda ocorre um amplo processo de ocupação voltado para a produção de grãos, além do cultivo da cana-de-açúcar, devido ao avanço da fronteira agrícola sobre o estado de Mato Grosso, iniciado a partir das décadas de 1960 e 1970, promovidos pelos planos e políticas governamentais de ocupação no Cerrado - II PND, PIN, POLOCENTRO, PRODECER e outros (VOLOCHKO, 2013).

O uso da terra na área de estudo possibilita averiguar significativa ocorrência de áreas com atividades ligadas à pecuária bovina extensiva principalmente na porção sul, sudeste e nordeste, que conforme JESUZ et al., (2013) ocupa cerca de 33\% da área total da bacia. Por outro lado nas porções sul, sudoeste, norte e noroeste, há o predomínio de atividades agrícolas, como o milho, cana-de-açúcar, algodão e a soja, representando uma área de $45 \%$ da bacia do Tenente Amaral. Fato favorecido principalmente, pelas condições morfológicas das formas do relevo plano e levemente colinoso, facilitando 0 uso dos maquinários no manejo dos solos destinados a prática agrícola empresarial (JESUZ, 2014). 


\section{A MORFODINÂMICA DA BACIA HIDROGRÁFICA DO RIO TENENTE AMARAL - MT}

\section{MATERIAIS E MÉTODOS}

O trabalho foi desenvolvido em três etapas, onde a primeira (Gabinete) consistiu na obtenção de levantamento do referencial teórico e obtenção, correção e re-projeção das bases disponíveis de informações relacionadas aos atributos do meio físico (área territorial da bacia, hidrografia, clima, solos, litoestratrigrafia, clinografia e hipsometria) e socioeconômico e uso da terra da bacia hidrográfica do rio Tenente Amaral.

As atividades de gabinete consistiram no levantamento e determinação dos mapas temáticos sobre o Clima, Estratigrafia, Clinografia, Hispsometria e das Unidades Pedológicas, encontrados nas bases cartográficas da Secretaria de Estado Planejamento e Coordenação Geral de Mato Grosso - SEPLAN/MT - 2007. Análises e a fotointerpretação das imagens dos satélites SPOT TM5 (SEMA/MT) e LANDSAT TM 5/7 (INPE); e tratamento dos dados obtidos do Modelo Digital de Elevação da Terra - MDE (Projeto TOPODATA/INPE). Em consonância com as diretrizes gerais do Instituto Brasileiro de Geografia e Estatística - IBGE, que regula as questões de procedimentos técnicos das bases geodésicas utilizadas em território brasileiro, os mapas-base e os temáticos foram reprojetados para o Sistema de Referência Geocêntrico para as Américas - SIRGAS 2000.

A delimitação da bacia do rio Tenente Amaral utilizou técnicas de geoprocessamento por meio do software ArcGIS 9.3. Esta etapa do trabalho correspondeu-a alguns ajustes em relação à quantidade e distribuição espacial dos cursos d'água, especialmente os de $1^{\mathrm{a}}$ e $2^{\mathrm{a}}$ ordem, usando o método de interpolação de camadas (sobreposição de layers), por fotointerpretação das imagens do satélite SPOT TM5, de resolução espacial de $10 \mathrm{~m}$, nas bandas multiespectrais e $2,5 \mathrm{~m}$ na banda pancromática. Esse procedimento contemplou os rios de $1^{\underline{a}}$ e $2^{\underline{a}}$ ordem devido aos problemas de exclusão de vários nas bases cartográficas do Instituto Brasileiro de Geografia e Estatística - IBGE de 1975

Os mapas representando as Características Básicas Estacionais (clima), Litoestratigrafia e das Unidades Pedológicas foram obtidos do material editado pela SEPLAN (2007), em escala de 1:250.000. Enquanto, os mapas clinográfio 


\section{A MORFODINÂMICA DA BACIA HIDROGRÁFICA DO RIO TENENTE AMARAL - MT}

e hipsométrico foram gerados a partir do Modelo Digital de Elevação da Terra MDE, disponibilizado pelo Projeto TOPODATA/INPE, proveniente dos dados da SRTM (Shuttle Radar Topography Mission).

A elaboração do Mapa Geomorfológico da bacia em questão levou em consideração as diferentes unidades morfoesculturais presentes em sua área, ou seja, o Planalto dos Guimarães e a Depressão Interplanáltica de Rondonópolis. Com base nas suas características estruturais/esculturais bem definidas através de análises fotointerpretativas, foi possível estabelecer dois arquivos shapfiles na interface do software de geoprocessamento ArcGIS 9.3 Depressão de Rondonopolis_BHTA e Planalto dos Guimarães_BHTA -, constituindo as superfícies de ocorrência das morfoesculturas homônimas. A delimitação das unidades geomorfológicas da bacia hidrográfica também teve suporte nas informações obtidas nas imagens dos satélites SPOT 5 (SEMA/MT), de alta resolução $(10 \mathrm{~m})$, do ano de 2007, e do LANDSAT 5 (INPE), do ano de 2011, nas bandas 543 e 721/543, conforme registrado na Figura 02, respectivamente, as quais possibilitaram análises de forma abrangente dos processos morfodinâmicos do relevo no contexto geral da área.

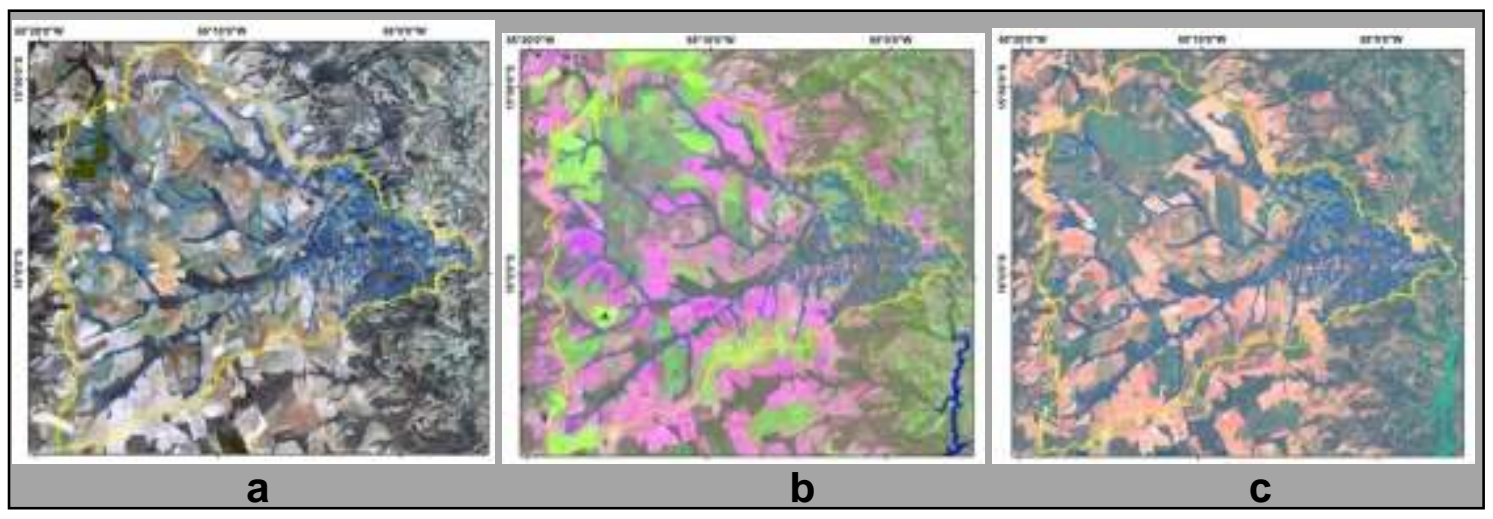

Figura 02: Imagens de satélites utilizadas na interpretação visual das unidades geomorfológicas e taxonômicas da bacia do rio Tenente Amaral-MT: a) SPOT 5 - Bandas: 543; b) LANDSAT 5 - Bandas: 721; e c) LANDSAT 5 - Bandas: 543.

Nesta etapa da pesquisa também foi efetivado vários levantamentos de campo durante os anos de 2013 e 2014, para realizar reconhecimento in loco dos locais de amostragem pré-definidos durantes as análises de gabinete. Nestes foram realizadas a descrição da área e registros fotográficos 
georreferenciados das feições geomorfológicas determinadas no trabalho do mapeamento geomorfológico.

A terceira e última etapa consistiu na elaboração e análise dos materiais cartográficos produzidos, por intermédio de discussões referentes ao arranjo das feições morfodinâmicas encontradas no limite territorial da bacia do rio Tenente Amaral, utilizando-se da proposta metodológica da classificação taxonômica do relevo apresentada por Ross (1991).

\section{RESULTADOS E DISCUSSÃO}

Os resultados obtidos representam o entendimento mais detalhado sobre a morfodinâmica dos processos que respondem pelas diferentes formas topográficas na Bacia hidrográfica do rio Tenente Amaral, mostrando a relação direta entre as classes clinográficas e hipsométricas com a distribuição espacial das feições geomorfológicas (VESTENA et al., 2011; MAIA e BEZERRA, 2011; HARTWIG e RICCOMINI, 2010). Sendo apresentando como produto final dessa relação o mapa geomorfológico da referida bacia em escala de melhor detalhe.

O mapa Hipsométrico da bacia do rio Tenente Amaral (Figura 03) apresenta cinco classes de fatiamento em um intervalo de altitudes máxima e mínima de 856,5 a 233,9 m respectivamente, representando uma amplitude de 622,6 metros em um intervalo de distância longitudinal médio de 50 km ( $E-W)$. Essas classes hipsométricas expressam, de certo modo as diferentes unidades morfoesculturais presentes na área da bacia, assim como suas feições geomorfológicas mapeadas, especialmente as localizadas na Depressão Interplanáltica de Rondonópolis. 


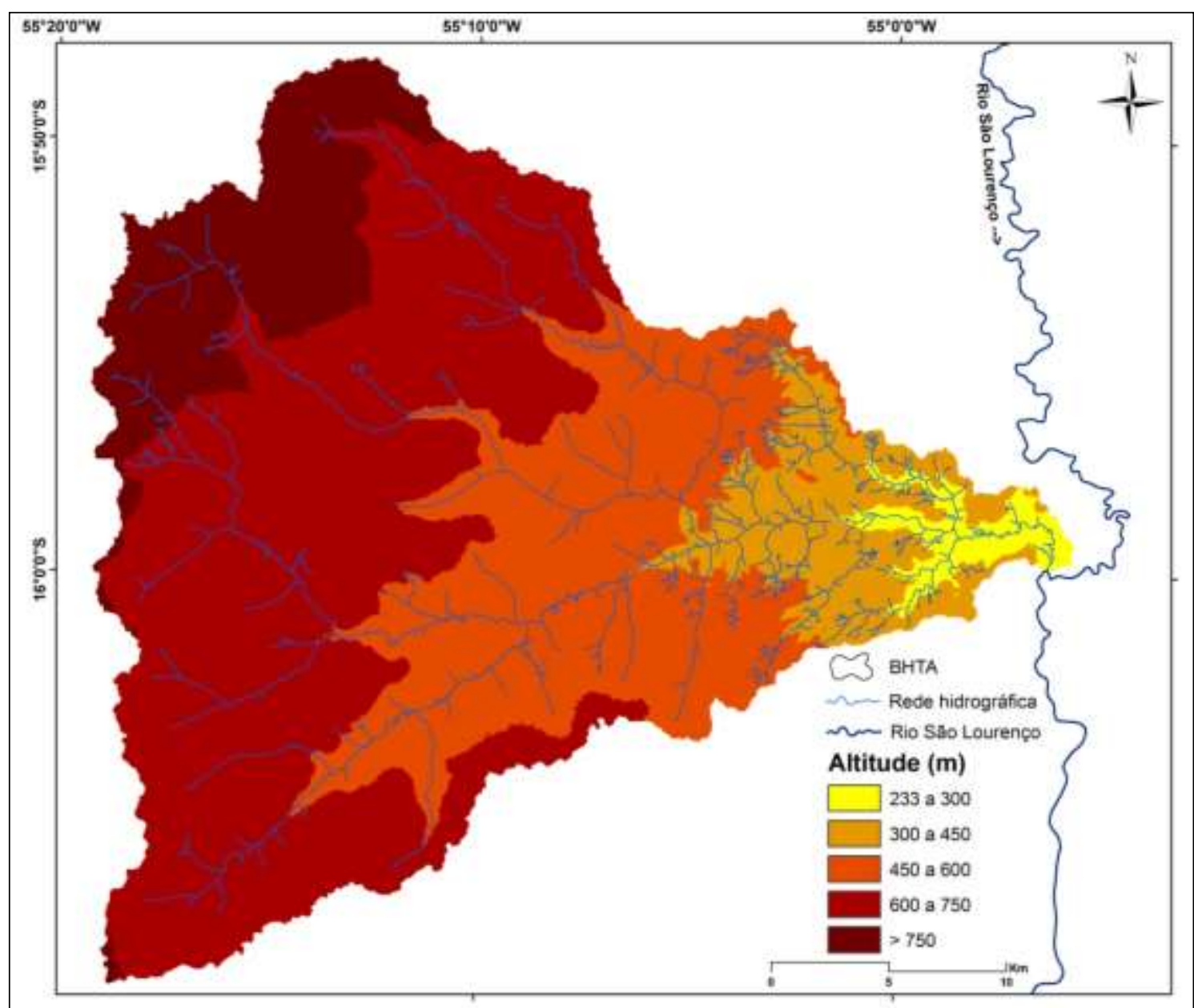

Figura 03: Mapa Hipsométrico da bacia do rio Tenente Amaral. Fonte: SRMT/TOPODATA/INPE.

Os níveis de maior elevação (> 750, 750-600 e 600-450 m), correspondentes às superfícies da unidade morfoescultural do Planalto dos Guimarães, caracterizam-se no contexto analisado como sendo a área de maior extensão territorial, ocupando mais de $80 \%$ da área total, e consequentemente com a maior intervenção social, devido às condições físicobióticas encontradas, especialmente pela "estabilidade" de suas unidades litopedológicas, este último representado pelo grupo dos Latossolos (com maior representatividade dos vermelhos e vermelho-amarelos). Além disso, as condições clinográficas, com classes de baixos declives, fato que possibilita a instalação de uma intensa e contínua utilização pelo setor agropecuário e agroindustrial. 


\section{A MORFODINÂMICA DA BACIA HIDROGRÁFICA DO RIO TENENTE AMARAL - MT}

Nas três classes hipsométricas de maior altitude, encontram-se as grandes parcelas com eventos de erosão mecânica e superficial da bacia do rio Tenente Amaral, principalmente nas áreas de cabeceiras de drenagem, onde estão localizados os processos de voçorocamentos, que conforme Jesuz et al., (2013), foram mapeados 39 processos, com uma ocorrência espacial de média de $20 \mathrm{~km}^{2}$.

Em muitos casos esses eventos de erosão mecânica estão relacionados com a presença dos Neossolos Quartzarênicos e Latossolos de textura média, variedades de solos com acentuado grau de fragilidade (LUZ et al., 2015). Algo reforçado pelo sistema de manejo adotado pelas praticas de produção agropastoril, onde se nota execução de técnicas de controle dos processos mecânicos erosivos.

Os níveis topográficos das superfícies mais rebaixadas estão entre 233 a 450 metros. Representando conjunto de formas do relevo da unidade da Depressão Interplanáltica de Rondonópolis, com eventos de exumação das superfícies do Planalto dos Guimarães, propriamente dita, expressando características intrínsecas às unidades geomorfológicas dissecadas no Estado de Mato Grosso, conforme destacados por Ross (1992) e Camargo (2011).

Nos níveis topográficos representados pelas classes hipsométricas entre 233 a 450 metros se destacam as feições geomorfológicas de superfícies exumadas, escarpas, morros testemunhos e depósitos coluvionares em grande parte do vale onde se encontra, de forma encaixada, o setor de "baixo" curso do rio Tenente Amaral e as superfícies exumadas propriamente ditas. Estas formas são mantidas por unidades lito-pedológicas do Grupo Ivaí e Formação Furnas, constituídas por arenitos consolidados, onde estão presentes ocorrem os Argissolos Vermelho-Amarelo derivados do material proveniente do processo de avanço do front de recuo das superfícies planálticas, onde as estruturas destes passam a constituir os depósitos coluvionares distribuídos ao longo dos sopés das escarpas, e ao preencher os vales constituem o material de origem da classe de solos supracitada. 
No setor da Depressão Interplanáltica de Rondonópolis, as formas de uso se diferem das desenvolvidas no setor do Planalto do Guimarães. As atividades são mais diversificadas e estão relacionadas com o aproveitamento das quedas d'água para produção de energia, por meio de Pequenas Centrais Hidrelétricas - PCH's e inúmeros balneários destinadas a prática do ecoturismo e esportes radicais aquáticos, bem como pequenas propriedades rurais que desenvolvem produção agropecuária no sistema de agricultura familiar/camponesa com destaque para a produção hortifruti e pecuária. Em termos dos processos da dinâmica superficial, neste setor da bacia hidrográfica, destacam-se os processos vinculados aos eventos de erosões provenientes de quedas de blocos, e pontos isolados de erosão mecânica por voçorocamento, além de erosão superficial.

O mapa Clinográfico, representado na figura 04 mostra a espacialidade das variações dos declives das vertentes existentes nas duas unidades morfoesculturais da bacia do rio Tenente Amaral. É evidente o contraste entre as vertentes do Planalto dos Guimarães e da Depressão Interplanáltica de Rondonópolis. 


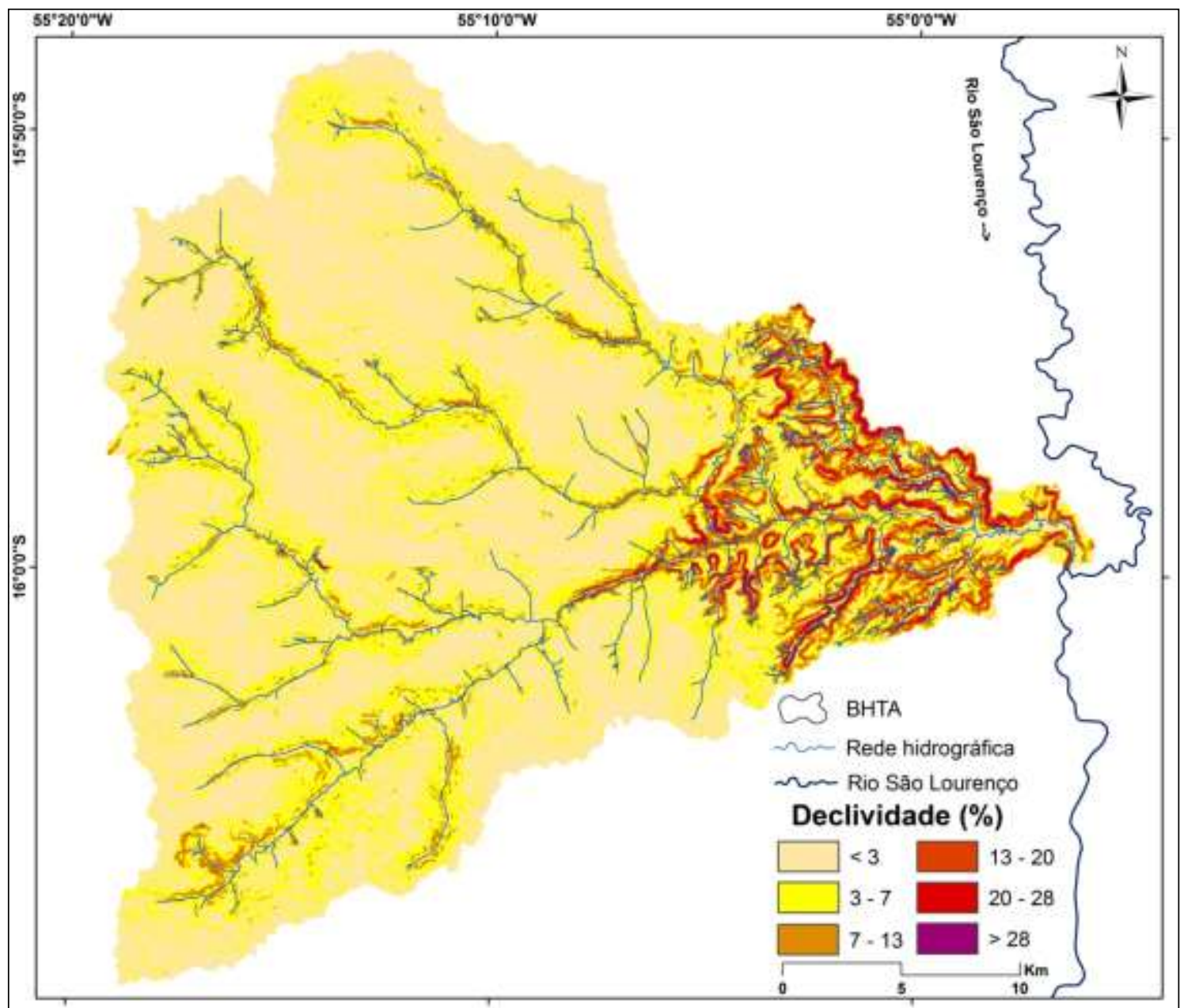

Figura 04: Mapa Clinográfico da bacia do rio Tenente Amaral. Fonte: SRMT/TOPODATA/INPE.

Essa temática também está evidenciando os contrastes entre as duas principais unidades de relevo na bacia do rio Tenente Amaral. Sobre essa questão verifica-se que a maior diversidade em termos clinográficos ocorre na área da Depressão Interplanáltica de Rondonópolis, superfície do médio e baixo curso do rio Tenente Amaral, onde sucede todas as classes, expressando à diversidade dos processos vinculados a dinâmica de superfície devido ao avanço do front de recuos das superfícies planálticas na região. Nota que as classes de 20 a 28 e maior que $28 \%$, se restringem a essa unidade morfoescultural. Por outro lado, a diversidade na inclinação das vertentes representa a diferenciação de feições geomorfológicas, fato que expressa a intensidade dos processos morfodinâmicos mecânicos nesta parte da bacia hidrográfica. 


\section{A MORFODINÂMICA DA BACIA HIDROGRÁFICA DO RIO TENENTE AMARAL - MT}

Em termos gerais os diferentes tipos de formas tem a seguinte relação com as declividades consideradas $\mathrm{n}$ trabalho: Escarpas com declives maiores que $28 \%$, áreas com depósitos coluvionares com 13 a $20 \%$ e 20 a $28 \%$, e morros testemunhos, superfícies exumadas e fundos e vales encaixados em "V" com formas de relevo expressas por declives menores que $3 \%$ de 3 a $7 \%$ e 7 a $13 \%$.

No setor do Planalto dos Guimarães, tem-se uma aparente "estabilidade" em termos de dinâmica dos processos superficiais, levando em consideração os valores em termos de declive das vertentes, pois a maior parte das parcelas deste setor da bacia hidrográfica apresnta formas de relevo com declives menores que $3 \%$ e 3 a $7 \%$, expressando uma superfície em condições relativamente plana, com setores muito planos nos topos dos interflúvios e bordas, com declives mais acentuados, rumo aos cursos d'água. Assim, foi possível aferir as condições clinográficas capazes de condicionar os processos de erosão superficial em áreas de agropecuária e vegetação nativa primária e/ou secundária no setor do Planalto e Chapada dos Guimarães na bacia do rio Tenente Amaral.

As áreas onde se encontram as classes de 7 a $13 \%$ e 13 a 20\% também exprssa as superfícies de fundos de vales e setores exumados na morfoescultura do Planalto dos Guimarães, principalmente nos pontos de contado entre as duas unidades morfoesculturais. Neste também foi possível verificar a presença pequenas áreas na classe de declives intermediários para acentuados (13 a $20 \%$ ), provavelmente correspondentes aos declives condicionados pelos vales com voçorocamento e/ou entalhamento dos tributários do setor de alto curso do rio Tenente Amaral. As proporções das classes hipsométricas e clinográficas contidas nas morfoesculturas do Planalto dos Guimarães e a Depressão Interplanáltica de Rondonópolis estão sendo apresentadas nas Tabelas 01 e 02, respectivamente. 
Tabela 01: Espacialidade das classes hipsométricas nas morfoesculturas da bacia do rio Tenente Amaral.

\begin{tabular}{c|c|c}
\hline Morfoesculturas & $\begin{array}{c}\text { Classes Hipsométricas } \\
(\mathbf{m})\end{array}$ & Distribuição espacial $\left.\mathbf{( k m}^{\mathbf{2}}\right)$ \\
\hline $\begin{array}{c}\text { Depressão } \\
\text { Interplanáltica } \\
\text { de }\end{array}$ & $233-300$ & 22,17 \\
\cline { 2 - 3 } $\begin{array}{c}\text { Rondonópolis } \\
\text { Intermediário }\end{array}$ & $300-450$ & 80,91 \\
\hline $\begin{array}{c}\text { Planalto dos } \\
\text { Guimarães }\end{array}$ & $450-600$ & 231,04 \\
\cline { 2 - 3 } & $600-750$ & 400,60 \\
\hline Total & $>750$ & 114,28 \\
\hline Adaptado de: & & \pm 849
\end{tabular}

Adaptado de: JESUZ, 2014.

Tabela 02: Espacialidade das classes clinográficas nas morfoesculturas da bacia do rio Tenente Amaral.

\begin{tabular}{c|c|c}
\hline Morfoesculturas & $\begin{array}{c}\text { Classes Clinográficas } \\
(\%)\end{array}$ & Distribuição espacial $\mathbf{( k m}^{\mathbf{2}} \mathbf{c}$ \\
\hline $\begin{array}{c}\text { Planalto dos } \\
\text { Guimarães }\end{array}$ & $<3$ & 436,52 \\
\hline \multirow{2}{*}{ Intermediário } & $3-7$ & 262,43 \\
\cline { 2 - 3 } & $7-13$ & 69,96 \\
\hline $\begin{array}{c}\text { Depressão } \\
\text { Interplanáltica } \\
\text { de }\end{array}$ & $13-20$ & 24,86 \\
\cline { 2 - 3 } Rondonópolis & $20-28$ & 9,85 \\
\hline Total & $>28$ & 3,34 \\
\hline
\end{tabular}

Adaptado de: JESUZ, 2014.

As análises das classes hipsométricas e clinográficas aplicadas à bacia do rio Tenente Amaral geraram resultados quanto às feições geomorfológicas existentes em sua área, assim como propiciaram o mapeamento de suas características, que juntas foram organizadas cartograficamente, resultando no Mapa Geomorfológico da Bacia Hidrográfica do Rio Tenente Amaral, apresentado na Figura 05. O mapa foi produzido levando-se em conta as classes supracitadas de altitude e declive do relevo e a partir da proposta de classificação taxonômica de Ross (1992). 


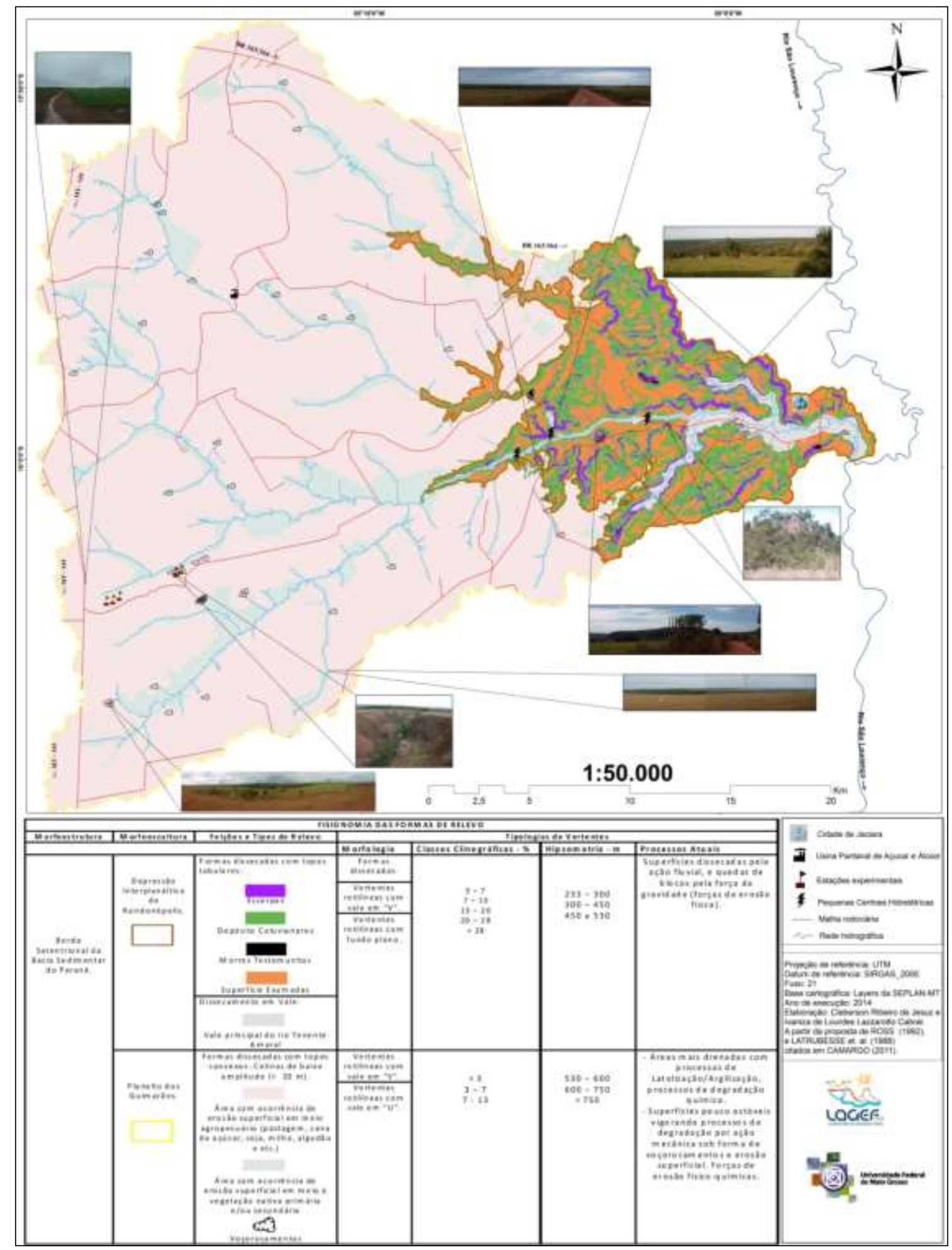

Figura 05: Mapa Geomorfológico da Bacia Hidrográfica do rio Tenente Amaral, Jaciara - MT.

Os três primeiros níveis taxonômicos foram identificados e caracterizados tendo como base a porção espacial em que a bacia hidrográfica 


\section{A MORFODINÂMICA DA BACIA HIDROGRÁFICA DO RIO TENENTE AMARAL - MT}

do rio Tenente Amaral se encontra na conjuntura regional, ou seja, a região sudeste do Estado de Mato Grosso.

O 1ํ nível taxonômico apresenta a macroforma estrutural, no qual parte do sul-sudeste do Estado de Mato Grosso se insere, sendo a Borda Setentrional da Bacia Sedimentar Paleo-Mesozóica do Paraná. O Planalto dos Guimarães e a Depressão Interplanáltica de Rondonópolis correspondem à Unidade Morfoescultural do $2^{\circ}$ nível taxonômico, sendo a primeira unidade constituída por superfícies com as maiores altitudes da região (em torno de 900 metros), colinas amplas e topos planos, enquanto a segunda unidade morfoescultural apresenta altitude média de 400 metros e se caracteriza pela área de exumação do próprio Planalto dos Guimarães.

No 3ำ nível taxonômico, na unidade correspondente a morfoescultura do Planalto dos Guimarães, temos as formas com topos convexos e as colinas de baixa amplitude $( \pm 20 \mathrm{~m})$. Enquanto, na morfoescultura da Depressão Interplanáltica de Rondonópolis, encontram-se as formas dissecadas com topos tabulares e o entalhamento do sistema de drenagem em vales encaixados, formando pequenas gargantas.

No 4ํㅡㅁel taxonômico, na morfoescultura da Depressão Interplanáltica de Rondonópolis, são definidas as seguintes formas do relevo: linhas de escarpas; depósitos coluvionares nos sopés das escarpas; e morros testemunhos. Na morfoescultura do Planalto dos Guimarães, encontramos as superfícies exumadas do próprio planalto, condicionantes da formação das áreas de depressão.

O $5^{0}$ nível taxonômico refere-se às formas dissecadas com vertentes retilíneas em vales em forma de "V" e "U", e vales com fundos planos, caracterizando as formas de degradação do relevo. Enquanto, o 6o nível taxonômico expõe os processos morfodinâmicos que apresentam certo grau de equivalência em relação às suas ocorrências temporais, ou seja, ocorrem praticamente paralelos e estão dispostos nas duas unidades morfoesculturais mapeadas/descritas do $2^{\circ}$ Táxon. 
Desta forma, foi possível identificar e representar as formas contemporâneas de áreas com ocorrência de erosão superficial em meio agropecuário, meio com vegetação nativa primária e/ou secundária, além de processos de erosão mecânica do tipo voçorocamentos, na unidade do Planalto dos Guimarães.

Enquanto isso, na unidade da Depressão Interplanáltica de Rondonópolis, encontram-se as formas de Escarpas e Depósitos Coluvionares, que apresentam forças correlacionadas, pois quando há ampliação das áreas de escarpas, devido à erosão por quedas de blocos, consequentemente, ocorre a ampliação das áreas de depósitos coluvionares em seus sopés. A proporção destas áreas na bacia hidrográfica em questão está sendo representado no Quadro 01. 
Quadro 01: Quantificação das formas contemporâneas analisadas n 6ำ Táxon da Bacia Hidrográfica do Rio Tenente Amaral, Jaciara - MT.

\begin{tabular}{|c|c|c|c|c|c|}
\hline 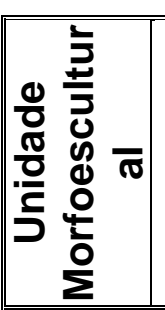 & 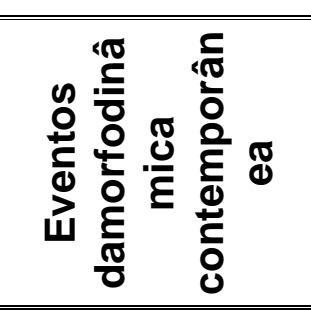 & 这 & 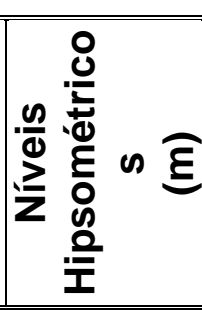 & 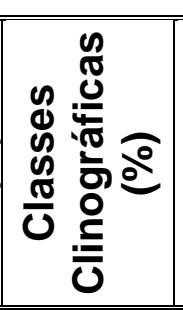 & Observações \\
\hline \multirow{3}{*}{ 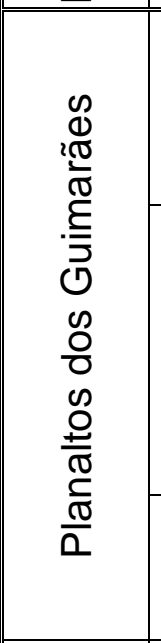 } & $\begin{array}{c}\text { Erosão } \\
\text { superficial em } \\
\text { meio } \\
\text { agropecuário }\end{array}$ & $\begin{array}{c}614,2 \\
3\end{array}$ & $\begin{array}{c}300-450 \\
450-600 \\
>750\end{array}$ & $\begin{array}{l}<3 \\
3-7\end{array}$ & $\begin{array}{c}\text { Algumas áreas } \\
\text { apresentam } \\
\text { declividades entre } 7- \\
13 \% \\
\end{array}$ \\
\hline & $\begin{array}{c}\text { Erosão } \\
\text { superficial em } \\
\text { meio de } \\
\text { vegetação } \\
\text { nativa primária } \\
\text { e/ou secundária }\end{array}$ & $\begin{array}{c}101,2 \\
6\end{array}$ & $\begin{array}{c}300-450 \\
450-600 \\
>750\end{array}$ & $\begin{array}{c}3-7 \\
7-13\end{array}$ & $\begin{array}{c}\text { Algumas áreas } \\
\text { apresentam } \\
\text { declividades entre 13- } \\
20 \%\end{array}$ \\
\hline & $\begin{array}{c}\text { Voçorocamento } \\
\text { s }\end{array}$ & 0,80 & $\begin{array}{c}300-450 \\
450-600 \\
>750 \\
\end{array}$ & $\begin{array}{c}<3 \\
3-7 \\
7-13\end{array}$ & $\begin{array}{c}\text { Foram mapeadas } 39 \\
\text { voçorocas } \\
\text { (JESUZ et al., 2013) }\end{array}$ \\
\hline \multirow{2}{*}{ 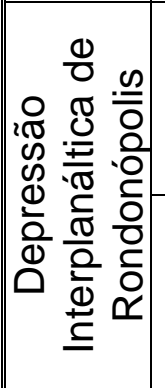 } & $\begin{array}{l}\text { Recuo e queda } \\
\text { de blocos. }\end{array}$ & 12,79 & $\begin{array}{l}233-300 \\
300-450\end{array}$ & $\begin{array}{c}20-28 \\
>28\end{array}$ & $\begin{array}{c}\text { Algumas áreas } \\
\text { apresentam } \\
\text { hipsometria entre 450- } \\
600 \mathrm{~m} \\
\end{array}$ \\
\hline & $\begin{array}{l}\text { Depósitos } \\
\text { Coluvionares }\end{array}$ & 68,47 & $\begin{array}{l}233-300 \\
300-450\end{array}$ & $\begin{array}{c}7-13 \\
13-20\end{array}$ & $\begin{array}{c}\text { Algumas áreas } \\
\text { apresentam } \\
\text { hipsometria entre 450- } \\
600 \mathrm{~m}\end{array}$ \\
\hline
\end{tabular}

Fonte: Autores.

De acordo com as informações destacadas no Quadro 1, percebe-se que os processos de erosão superficial se destacam em meio de uso agropecuário quanto em meio a vegetação nativa primária e/ou secundária, correspondendo cerca de $85 \%$ de toda a distribuição espacial localizada na bacia, envolta na morfoescultura do Planalto dos Guimarães, denotando uma relação direta com as áreas de uso agropecuário e agroindustrial da mesma, preferencialmente locadas nas classes hipsométricas dos fatiamentos superiores, e de classes clinográficas entre $<3 \%$ a $13 \%$. 


\section{A MORFODINÂMICA DA BACIA HIDROGRÁFICA DO RIO TENENTE AMARAL - MT}

\section{CONSIDERAÇÕES FINAIS}

O presente estudo efetivou uma análise e das feições geomorfológicas da bacia do rio Tenente Amaral - MT, sob a perspectiva da compreensão dos processos morfodinâmicos e fatores socioambientais, além da sua importância relativa ao contexto das nascentes nas superfícies planálticas.

O entendimento das condições hipsométricas e clinográficas da área subsidiaram a produção de dados sobre morfodinâmica nas superfícies da bacia, a ponto de apresentarem seus limites bem distintos e de possível visualização, que se utilizando dos recursos provenientes do SIG (ArcGIS 9.3 ESRI) foram interpretados, sobrepostos/interpolados gerando o Mapa Geomorfológico da bacia na escala de 1: 50.000, resultado importante para o desenvolvimento de futuros trabalhos não só para a análise da evolução das formas do relevo na região, como também para trabalhos sobre a fragilidade dos solos frente aos processos da dinâmica superficial, devido ao próprio detalhamento das informações que a escala do resultado do trabalho representa, podendo ser amplamente utilizadas em outras sub-bacias que compõem as cabeceiras do Alto rio São Lourenço.

Na escala proposta ao trabalho, foi possível identificar e mapear com as respectivas particularidades duas unidades morfoesculturais existentes na bacia hidrográfica do rio Tenente Amaral, ou seja, a Depressão Interplanáltica de Rondonópolis e o Planalto dos Guimarães, apresentando feições geomorfológicas de escarpas erosivas, depósitos coluvionares, superfícies exumadas, morros testemunhos e vales encaixados na primeira morfoescultura, e áreas com ocorrência de erosão superficial em meio agropecuário e de vegetação nativa primária e/ou secundária na segunda morfoescultura, assim como 39 eventos de voçorocamentos.

O estudo possibilitou verificar que ocorre uma realidade bastante complexa em relação à evolução das superfícies planálticas, especificamente as que compõem as cabeceiras das nascentes dos sistemas de drenagem que se dirigem para o Pantanal Setentrional mato-grossense (Planalto dos 
Guimarães), que apresentam usos da terra voltados quase exclusivamente para o setor agropecuário moderno (agronegócio). Implicando a utilização das informações apresentadas em futuros trabalhos voltados as tomadas de decisões sobre os aspectos ambientais.

\section{REFERÊNCIAS}

BORGES, M. E. S. Mapeamento geomorfológico da bacia do rio Preto e sua relação com uso agrícola. Dissertação de Mestrado. Universidade de Brasília, Brasília, DF., 2008.

BRASIL. DEPARTAMENTO NACIONAL DA PRODUÇÃO MINERAL. PROJETO RADAMBRASIL. Folha SD. 21. Cuiabá. Rio de Janeiro, 1982.

CABRAL, T. L.; CABRAL, I. L. L.; ROBAINA, L. E. S. Compartimentação Geomorfológica do município de Sorriso - MT. In: XV Simpósio Brasileiro de Geografia Física Aplicada. Vitória - ES. Anais do XV Simpósio Brasileiro de Geografia Física Aplicada, p. 623-631, 2013.

CAMARGO, L. (Org.). Atlas de Mato Grosso: abordagem socioeconômicoecológica. Entrelinhas, Cuiabá-MT, 2011.

CAMARGO, L. H. R. Geografia, Epistemologia e Método da Complexidade. Revista Sociedade e Natureza. 14 e 15 (26 a 29): 133-150. Uberlândia: Edufu, 2003.

CASSETI, V. Ambiente e apropriação do relevo. São Paulo: Contexto, 1991.

CASSETI, V. Geomorfologia. [S.I.]: [2005]. Disponível em: <http://www.funape.org.br/geomorfologia/>. Acesso em abril de 2013.

CHRISTOFOLETTI, A. As características da Nova Geografia. Geografia, Rio Claro, v. 1, n. 1, p. 3-33, 1976.

DREW, D. Processos interativos Homem-Meio Ambiente. (Tradução: João Alves dos Santos. Revisão: Suely Bastos). - São Paulo: DIFEL, 1986.

EMPRESA BRASILEIRA DE PESQUISA AGROPECUÁRIA - EMBRAPA. Sistema Brasileiro de Classificação de Solos - SBCS. [Editores Técnico: SANTOS, H. G. et. al.]. - 2ª ${ }^{a}$ ed. - Rio de Janeiro: EMBRAPA SOLOS, 2006.

EMPRESA BRASILEIRA DE PESQUISA AGROPECUÁRIA. Sistema Brasileiro de Classificação de Solos. Rio de Janeiro, 1999. 412p.

FERREIRA, V. de O. A abordagem da paisagem no âmbito dos estudos ambientais integrados GeoTextos, vol. 6, n. 2, dez. 2010. 187-208.

FURRIER, M. F.; NÓBREGA, W. R.; SOUZA, A. S. Análise morfométrica e morfotectônica do Gráben do rio Mamanguape e adjacências, borda oriental do estado da Paraíba, Brasil. Revista do Departamento de Geografia - USP, Volume 28 (2014), p. 25-38. 
HARTWIG, M. E.; RICCOMINI, C. Análise morfotectônica da região da Serra dos Órgãos, Sudeste do Brasil. Revista Brasileira de Geomorfologia, v. 11, $\mathrm{n}^{\circ}$ 1, p. $11-20,2010$

JESUZ, C. R. Estudo geomorfológico e a análise dos processos de erosão mecânica na bacia hidrográfica do rio Tenente Amaral - MT. 2014, fls. 142. Dissertação (Mestrado em Geografia) - Universidade Federal de Mato Grosso, Instituto de Ciências Humanas e Sociais, Programa de Pós-Graduação em Geografia, Cuiabá, 2014.

JESUZ, C. R.; ITO, J. B. B,; PETER, Z. Erosões mecânicas na bacia hidrográfica do rio Tenente Amaral, Jaciara - MT, e suas determinantes socioambientais. Revista Mato-Grossense de Geografia - Cuiabá - n. 16 - p. 89-105 - jan/jun 2013.

LUZ, T. E. da.; LIMA, E. B. N. R.; SALOMÃO, F. X. T.; LIMA, Z. M. de. Morfopedologia aplicada à concepção de obras em microbacia do perímetro urbano de Várzea Grande-MT. Rev. Ambiente \& Água vol. 10 n. 3 Taubaté - Jul. / Sep. 2015, págs. 646-659.

MAIA, R. P.; BEZERRA, F. H. R. Neotectônica, geomorfologia e ambientes fluviais: uma analise preliminar do contexto nordestino. Revista Brasileira de Geomorfologia, v. 12, p. 37-46, 2011.

MAMEDE, L. Geomorfologia: abordagem sistêmica em uma microbacia. GEOGRAFARES, Vitória, v. 1, no 1, jun. 2000.

MENDONÇA, F. Geografia socioambiental. Terra Livre. AGB. São Paulo, n. 16, 2001, p. 113-132.

PEDROSA, A. S. A Geomorfologia Perante a ciência geográfica: algumas reflexões. Soc. \& Nat., Uberlândia, 26 (3): 409-417, set/dez/2014

REIS JÚNIOR, Dante Flávio da Costa. História de um pensamento geográfico: Georges Bertrand. GEOGRAFIA, Rio Claro, v. 32, n. 2, mai./ago. 2007b, p. 363-390.

RISER, J. Erosão e Paisagens Naturais. Flammarion, Paris. (Tradução de Antônio Viegas), 1995.

ROSS, J. L. S. Ecogeografia do Brasil: subsídios para planejamento ambiental. Oficina de Textos, São Paulo, 2006.

ROSS, J. L. S. Geomorfologia: ambiente e planejamento. Editora Contexto, São Paulo-SP. 1991.

ROSS, J. L. S. O Registro Cartográfico dos Fatos Geomorfológicos e a Questão da Taxonomia do Relevo. Revista do Departamento de Geografia, São Paulo; USP, №6, 1992. 
ROSS, J. L. S. O registro cartográfico dos fatos Geomorfológicos e a questão da taxonomia do relevo. Revista do Dep. de Geografia. $n^{\circ}$ 6. (17- 29) FFLCH/USP. São Paulo-SP. 1992.

SEPLAN. Secretaria de Estado de Planejamento e Coordenação Geral. Projeto de Desenvolvimento Agroambiental do Estado de Mato Grosso PRODEAGRO. Mato Grosso: solos e paisagens. Cuiabá - MT. 2007.

SUERTEGARAY, D. M. A.; NUNES, J. O. R. A natureza da Geografia Física na Geografia. Revista Terra Livre, ㄲo17, págs. 11 -24. São Paulo. 2o Semestre/2001.

TARIFA, J. R. Mato Grosso: clima: análise e representação cartográfica. (Série recursos naturais e estudos ambientais). Cuiabá, MT: Entrelinhas, 2011.

VESTENA L. R.; CHECCHIA, T.; KOBYIAMA, M. Análise morfométrica e geomorfológica da bacia hidrográgica do Caeté, Alfredo Wagner/SC. Bol. geogr., Maringá, v. 29, n. 2, p. 93-106, 2011.

VITTE, A. C. Considerações sobre a teoria da etchplanação e sua aplicação nos estudos das formas de relevo nas regiões tropicais quentes e úmidas. Terra livre, № 16, p. 11- 24, São Paulo, 2001.

VITTE, A. C. Da Ciência da Morfologia à Geomorfologia Geográfica. Uma contribuição à história do pensamento geográfico. Revista Mercator, $7, \mathrm{p}$. 10- 20, 2008.

VOLOCHKO, D. Da extensão do campo à centralização do urbano: elementos para o debate da produção do espaço em Mato Grosso. Revista Mato-Grossense de Geografia - Cuiabá - n. 16 - p. 18-38 - jan/jun 2013.

WWF-BRASIL. Monitoramento das alterações da cobertura vegetal e uso do Solo na Bacia do Alto Paraguai - Porção Brasileira - Período de Análise: 2008 a 2010. Iniciativa: $\mathrm{Cl}$ - Conservação Internacional, ECOA Ecologia e Ação, Fundación AVINA, Instituto SOS Pantanal, WWF- Brasil. Brasília, 2011. 